\title{
A new kinetic model for the photopolymerization shrinkage-strain of dental composites and resin-monomers
}

\author{
Mohammad Atai ${ }^{a, *}$, David C. Watts ${ }^{b}$ \\ a Iran Polymer and Petrochemical Institute (IPPI), P.O. Box 14965/115, Tehran, Iran \\ $\mathrm{b}$ Biomaterials Science Research Group, School of Dentistry and Photon Science Institute, The University of Manchester, \\ Manchester M15 6FH, UK
}

\section{A R T I C L E I N F O}

\section{Article history:}

Received 17 January 2006

Received in revised form 25 January

2006

Accepted 1 February 2006

\section{Keywords:}

Dental composites

Photopolymerization

Shrinkage

Kinetics

Kinetic model

Filler

\begin{abstract}
A B S T R A C T
Objectives. The aim of the study was to develop a new kinetic model for the shrinkage-strain rates of dental resin composites. The effect of filler content on the shrinkage-strain kinetics and degree of conversion of dental composites was also investigated.

Methods. A resin matrix containing $65 \mathrm{wt} . \%$ Bis-GMA and $35 \mathrm{wt} . \%$ TEGDMA was prepared. $0.5 \mathrm{wt} . \%$ camphorquinone and $0.5 \mathrm{wt} . \%$ dimethyl aminoethyl methacrylate were dissolved in the resin as photo-initiator system. Silanized glass fillers were added in different percentages to the resin-monomers. The shrinkage-strain of the specimens photopolymerized at circa $550 \mathrm{~mW} / \mathrm{cm}^{2}$ was measured using the bonded-disc technique at 23,37 and $45^{\circ} \mathrm{C}$ for the matrix monomers and $23^{\circ} \mathrm{C}$ for the composites. Initial shrinkage-strain rates were obtained by numerical differentiation of shrinkage-strain data with respect to time. Degreeof-conversion of the composites containing different filler contents was measured using FTIR spectroscopy.

Results. A new kinetic model was developed for the shrinkage-strain rate using the autocatalytic model of Kamal [Kamal MR, Sourour S. Kinetic and thermal characterization of thermoset cure. Polym Eng Sci 1973;13(1):59-64], which is used to describe the reaction kinetics of thermoset resins. The model predictions were in good agreement with the experimental data. The results also showed a linear correlation between the shrinkage-strain (and shrinkage-strain rate) and filler-volume fraction. The filler fraction did not affect the degreeof-conversion of the composites.

Significance. The rate of polymerization, determined via the shrinkage, being invariant with filler-fraction, suggests that only a relatively high filler-surface area, as may be obtained with nano-fillers, will affect the network-forming kinetics of the resin matrix.
\end{abstract}

(c) 2006 Academy of Dental Materials. Published by Elsevier Ltd. All rights reserved.

\section{Introduction}

Polymerization shrinkage during the photo-curing process of the resin-based dental composites is still a major drawback of these restorative materials. Polymerization shrinkage may lead to stress development on the cavity walls resulting in further marginal gaps, secondary caries and clinical failure of the restoration. The reduction of shrinkage has been the

\footnotetext{
* Corresponding author. Tel.: +9821 44580085; fax: +9821 44580023.

E-mail address: M.Atai@ippi.ac.ir (M. Atai).

0109-5641/\$ - see front matter @ 2006 Academy of Dental Materials. Published by Elsevier Ltd. All rights reserved. doi:10.1016/j.dental.2006.02.009
} 
subject of numerous studies which can be summarized in two categories: (i) materials development-reduction of the shrinkage by introducing new low-shrinking monomers [1-7], monomers with liquid crystalline structure which can reduce the shrinkage due to phase change during polymerization [8], reducing the shrinkage-induced stress using non-bonded fillers $[9,10]$, and incorporation of more fillers into the matrix phase using multimodal filler particle size distributions; and (ii) methods development-using different light irradiation regimes to reduce the shrinkage-induced stress [11,12], and various placement techniques aiming to relieve the stress [13-21].

Despite the extensive studies on the shrinkage-related subjects, the complex behavior of the materials during the lightcuring process is still not completely clear.

The photopolymerization process of multifunctional monomers and dental resin composites has mainly been studied using thermal analysis techniques [22-27] in which the exothermic reaction of the polymerization is monitored to determine the curing kinetics of the materials. Shrinkage is another phenomenon which can be considered as a method to study the polymerization kinetics of the dental resin-monomers. The authors in their previous work [28] studied the photo-curing behavior of dental resin-monomers by monitoring the polymerization shrinkage-strain of the materials. In this study, a new kinetic model is developed for the shrinkage-kinetics of the resin-monomers based on the autocatalytic model of Kamal [29,30].

Although research indicated that the filler content of dental composites plays an important role in the physical and mechanical properties of the materials [31-37], no systematic investigation has been made on the effect of filler on the shrinkage-strain kinetics. In the present work, the effect of filler loading on the shrinkage-strain kinetics and degree-ofconversion of dental composites is also studied.

\section{Materials and methods}

\subsection{Materials}

2,2-Bis[4-(2-hydroxy-3-methacryloyloxypropoxy)phenyl]propane (Bis-GMA) and triethylene glycol dimethacrylate(TEGDMA) were obtained from Rohm (Degussa group, Germany). N,N'-Dimethyl aminoethyl methacrylate (DMAEMA) and camphorquinone (CQ) were purchased from Fluka (Germany). Barium aluminum silicate glass filler was obtained from Ivoclar-Vivadent (Liechtenstein) and was silanized [38] with $1.5 \mathrm{wt} . \% \quad \gamma$-methacryloxy propyl trimethoxy silane ( $\gamma$-MPS, Fluka).

\subsection{Methods}

A mixture of 65 wt. $\%$ Bis-GMA and 35 wt. $\%$ TEGDMA was prepared as matrix phase. $0.5 \mathrm{wt}$.\% Camphorquinone and $0.5 \mathrm{wt} . \%$ $\mathrm{N}, \mathrm{N}^{\prime}$-dimethyl aminoethyl methacrylate, as light-curing initiator system, were dissolved in the matrix at sub-ambient light. The silanized filler was then added to the matrix in different percentages. The shrinkage-strain was measured using the bonded-disk technique [39], with a $3 \mathrm{~mm}$ thick glass base- plate. The specimens were photopolymerized for $40 \mathrm{~s}$ using a light source with an irradiance of circa $550 \mathrm{~mW} / \mathrm{cm}^{2}$ (Optilux 500 , USA). The shrinkage-strain rate was calculated by numerical differentiation of shrinkage-strain data with respect to time.

Degree of conversion of the composites and unfilled resin systems was measured using FTIR spectroscopy (EQUINOX 55, Bruker, Germany) at a resolution of $4 \mathrm{~cm}^{-1}$ and 32 scans in the range of $4000-400 \mathrm{~cm}^{-1}$. The samples were placed between two polyethylene films, pressed to form a very thin film and the absorbance peaks of the uncured samples were obtained. The samples were then light-cured for $40 \mathrm{~s}$ and the peaks were measured for the cured samples. Degree-of-conversion (DC\%) was determined from the ratio of absorbance intensities of aliphatic $\mathrm{C}=\mathrm{C}$ (peak at $1638 \mathrm{~cm}^{-1}$ ) against the internal reference aromatic C..C (peak at $1608 \mathrm{~cm}^{-1}$ ) before and after curing of the specimen. The degree of conversion was then calculated as follows:

$$
\begin{aligned}
\mathrm{DC} \%= & \left(1-\frac{\left(1637 \mathrm{~cm}^{-1} / 1608 \mathrm{~cm}^{-1}\right) \text { peak area after curing }}{\left(1637 \mathrm{~cm}^{-1} / 1608 \mathrm{~cm}^{-1}\right) \text { peak area before curing }}\right) \\
& \times 100
\end{aligned}
$$

The average size and specific surface area of the filler particles were measured using a particle-size analyzer (Analysette 22, Fritsch, Germany) and the BET method (ChemBET 3000, Quantachrome, USA), respectively.

The results (five repeats) were analyzed and compared using one-way ANOVA and the Tukey test at the significance level of 0.05 .

\section{Results}

Table 1 presents the average particle-size and specific surface area of the glass particulate fillers. Table 2 shows the shrinkage-kinetic parameters for the matrix resin $(65 \mathrm{wt} \%$ BisGMA and $35 \mathrm{wt} \%$ TEGDMA containing the photo-initiator sys-

\begin{tabular}{|c|c|c|}
\hline Filler & $\begin{array}{l}\text { Average particle } \\
\text { size }(50 \%, \mu \mathrm{m})\end{array}$ & $\begin{array}{l}\text { Specific surface } \\
\text { area }\left(\mathrm{m}^{2} / \mathrm{g}\right)\end{array}$ \\
\hline $\begin{array}{l}\text { Barium aluminum } \\
\text { silicate glass } \\
\text { (Ivoclar-Vivadent) }\end{array}$ & 3.4 & 3.7 \\
\hline
\end{tabular}
tem) at different temperatures.

Table 2 - Shrinkage kinetic parameters in accordance with Eq. (IV) for the matrix resin (65 wt.\% Bis-GMA and 35 wt.\% TEGDMA containing a photo-initiator system) at different temperatures

\begin{tabular}{llll}
$\mathrm{T}\left({ }^{\circ} \mathrm{C}\right)$ & $k\left(\mathrm{~s}^{-1}\right)$ & $m$ & $n$ \\
\hline 23 & 0.0007 & 1.77 & 3.4 \\
35 & 0.0011 & 1.5 & 3.1 \\
45 & 0.0014 & 1.6 & 2.95 \\
\hline
\end{tabular}




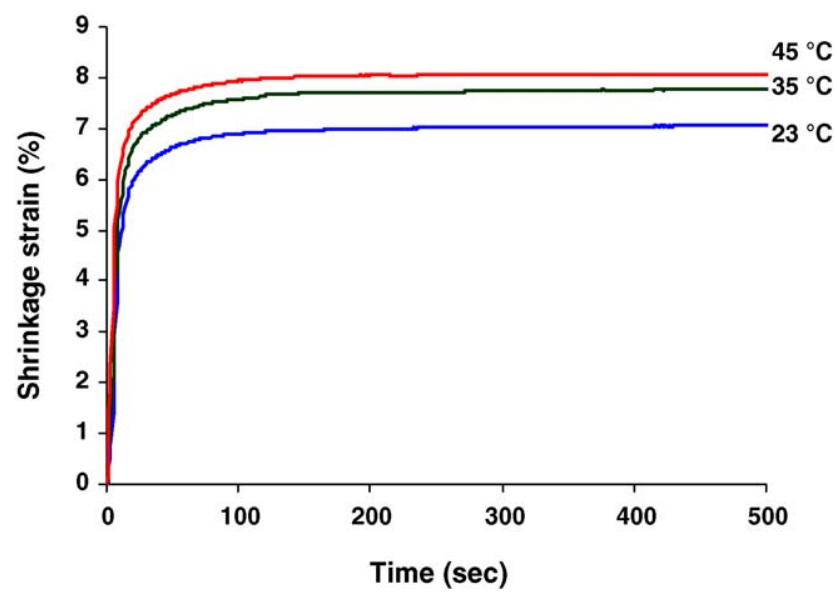

Fig. 1 - Shrinkage-strain of the resin matrix (65 wt.\% Bis-GMA, 35 wt.\% TEGDMA) at different temperatures.

Fig. 1 shows the shrinkage-strains and Fig. 2 illustrates the shrinkage-strain rates of the matrix resin-monomer at different temperatures which indicates that the shrinkagestrain and shrinkage-strain rate increased with increasing temperature. The pre-exponential parameter and the overall activation energy of shrinkage-strain were determined from Fig. 3. Fig. 4 shows the shrinkage-strain of the composites with different filler contents, and Fig. 5 denotes the linear correlation $\left(R^{2}>0.98\right)$ between filler-volume fraction and shrinkagestrain.

Fig. 6 shows the shrinkage-strain rates of the composites with different filler contents. The maximum shrinkage-strain rate decreased with filler-volume fraction $(p<0.05)$ (Fig. 7), but the time at the maximum was the same for all samples $(p>0.05)$ (Fig. 8).

Fig. 9 illustrates the degree-of-conversion of the composites with different filler loading. No significant difference was found between DC\% of the composites containing different filler-volume fractions ( $p>0.05)$. The degree-of-conversion was not affected by the filler fraction of the composites.

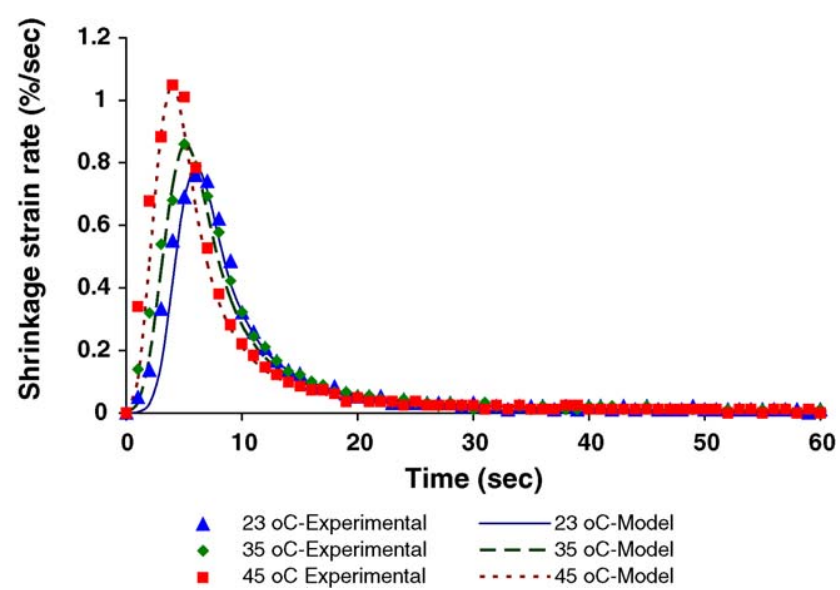

Fig. 2 - Shrinkage-strain rate of the resin-matrix (65 wt.\% Bis-GMA, 35 wt.\% TEGDMA) at different temperatures.

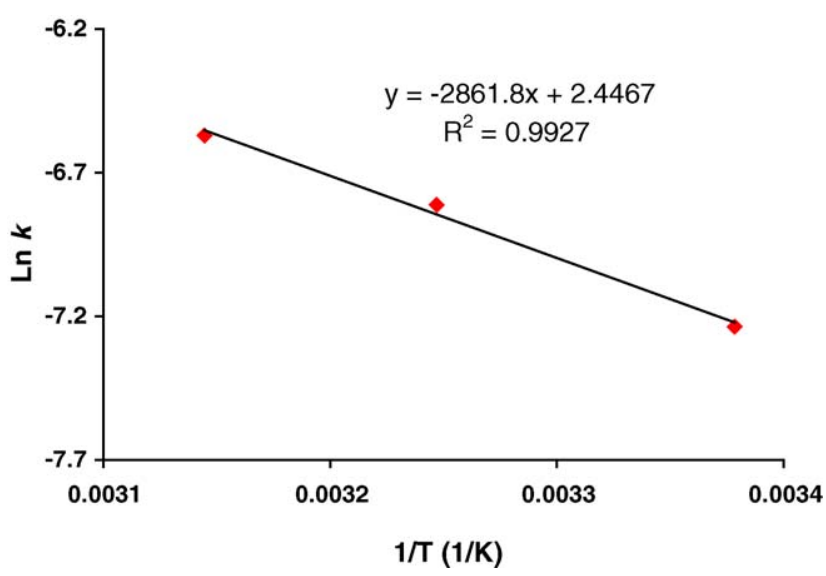

Fig. 3 - Rate constant variation with temperature: $\ln k$ vs. $1 / T$ for calculating kinetic parameters $A$ and $E$.

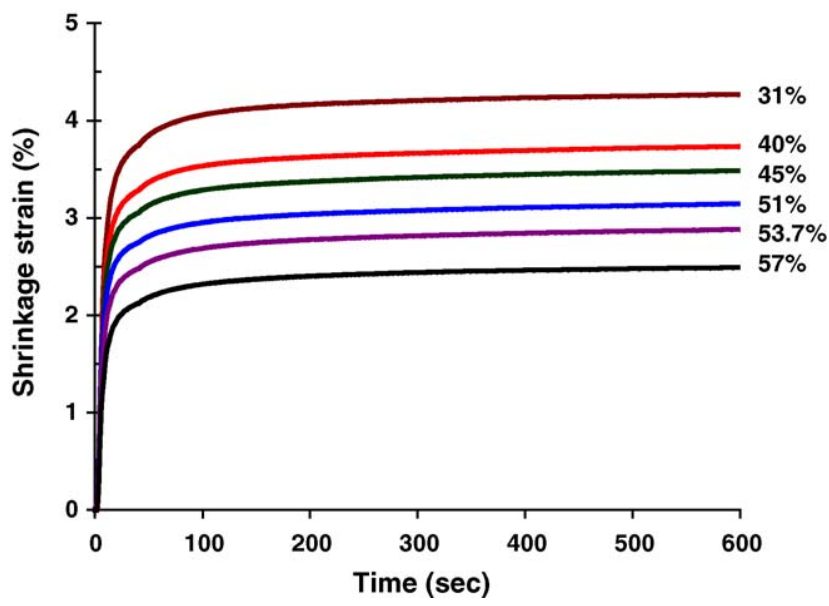

Fig. 4 - Shrinkage-strain vs. time for composites with varying filler content (vol\%).

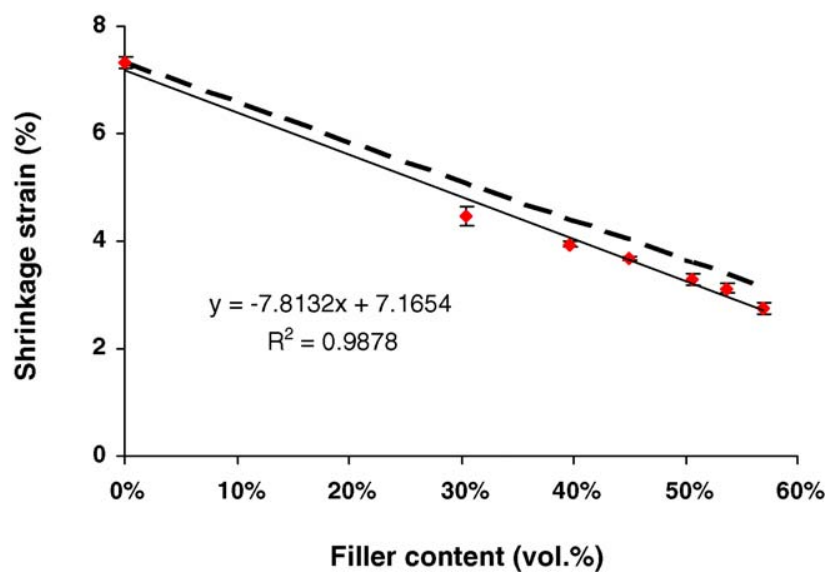

Fig. 5 - Correlation between shrinkage-strain and filler-fraction of the composites (at $\left.23^{\circ} \mathrm{C}\right)$ : $(\diamond)$ experimental, $(-)$ linear model and (-) mixture law. 


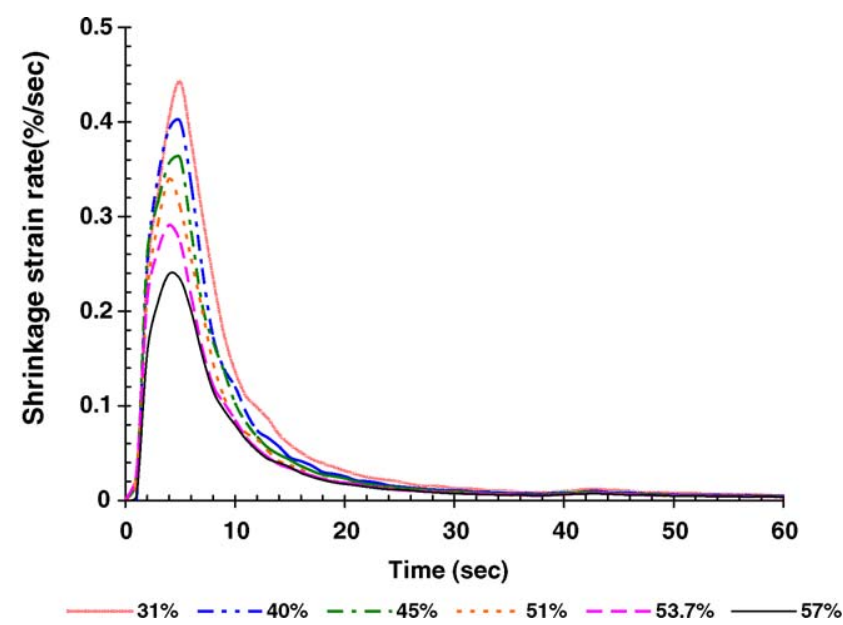

Fig. 6 - Shrinkage-strain rate vs. time for composites with varying filler-fraction (vol\%).

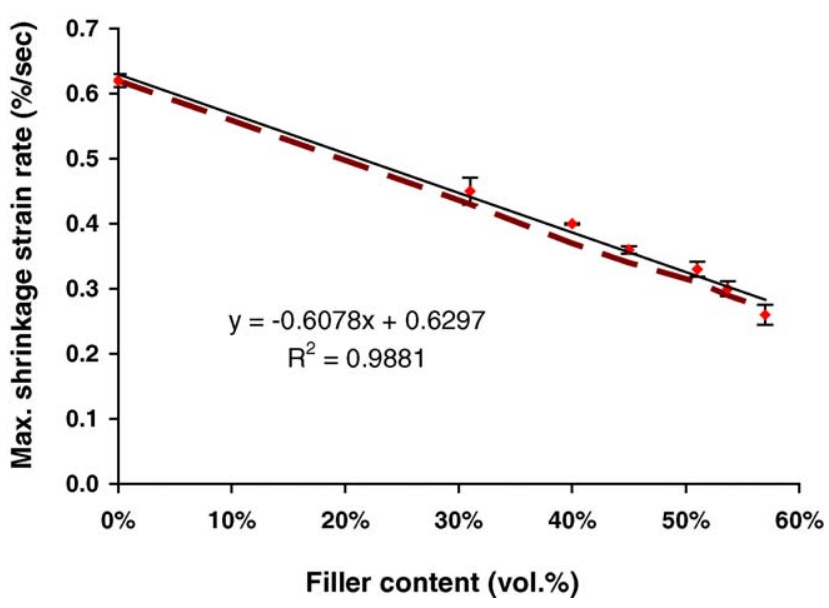

Fig. 7 - Maximum shrinkage-strain rate vs. filler-volume percent (at $\left.23^{\circ} \mathrm{C}\right)$ : $(\diamond)$ experimental, $(-)$ linear model and $(--)$ mixture law.

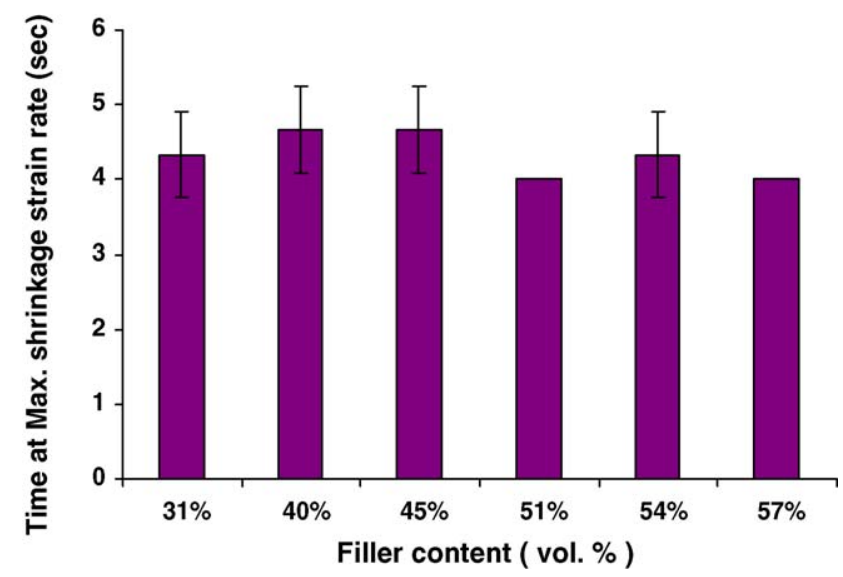

Fig. 8 - Time at maximum shrinkage-strain rate vs. filler-fraction (vol\%).

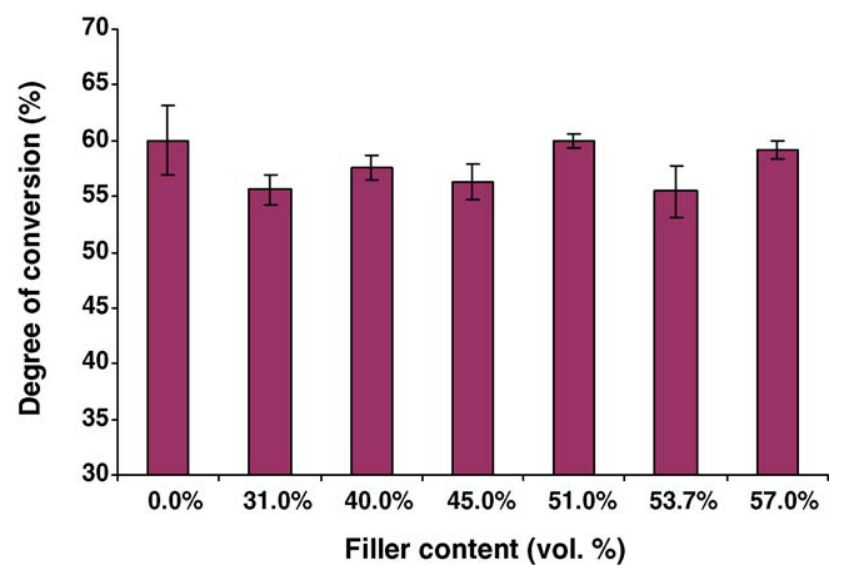

Fig. 9 - Degree-of-conversion vs. filler-fraction (vol\%).

\section{Discussion}

\subsection{Shrinkage-strain kinetics}

Polymerization shrinkage in dental composites is the result of conversion of intermolecular van der Waals distances of the resin-monomers to the covalent bond-lengths during light-curing [28]. As shrinkage is a consequence of the polymerization reaction it should follow the polymerization reaction pattern. Fig. 2 depicts the shrinkage-strain rate behavior of the monomers. The rising and falling parts of the shrinkage-strain rate, at the early stages of light-curing, represent the auto-acceleration and auto-deceleration stages of the polymerization reaction as seen in the polymerization of dimethacrylate monomers [40-42]. Photopolymerization and network formation of the multifunctional monomers in the presence of free-radical initiating systems follows radical chain polymerization in which the reaction rate is given by the following classical equation [43]:

$R_{\mathrm{P}}=k_{\mathrm{P}}[\mathrm{M}]\left(\frac{R_{\mathrm{i}}}{2 k_{\mathrm{t}}}\right)^{1 / 2}$

The equation shows the dependence of polymerization rate, $R_{\mathrm{P}}$, on the rate constant for propagation, $k_{\mathrm{P}}$, and on the square root of the rate constant for termination, $k_{\mathrm{t}}$, so:

$R_{P} \propto \frac{k_{P}}{k_{t}^{1 / 2}}$

It has been found that the polymerization reaction of multimethacrylates and multiacrylates is diffusion-controlled [44]. A few seconds after irradiation, the auto-accelerative gel effect is seen in which the segmental movement of radicals is restricted and termination becomes diffusion-controlled, leading to an increase in the polymerization rate. During this stage, $k_{\mathrm{t}}$ in Eq. (I) decreases and results in a dramatic increase in $R_{\mathrm{p}}$. Continuing the reaction, the system becomes more viscous and restricted so that the propagation reaction also becomes diffusion-controlled. At this stage, $k_{\mathrm{P}}$ in Eq. (I) also decreases leading to a fall in the polymerization rate. This decline in the rate is called auto-deceleration or the glass 
effect $[42,43]$, the latter relating to the onset of vitrification. These types of processes are often described by the model developed by Kamal $[29,30]$. The model equation is:

$\frac{\mathrm{d} \alpha}{\mathrm{dt}}=k \alpha^{m}\left(\alpha_{\mathrm{m}}-\alpha\right)^{n}$

where $\alpha$ represents the relative conversion, $k$ an Arrheniustype rate constant, $n$ the reaction order exponent and $m$ is the autocatalytic exponent. In this equation, $k \alpha^{m}$ represents the autocatalytic nature of the process [41]. $\alpha_{\mathrm{m}}$ is the maximum conversion, which is considered as 1 when the assumption of a completed reaction is made.

The autocatalytic model has also been used to describe the photo-initiated polymerization of dental resin-monomers and composite systems and multifunctional acrylates based on photo-DSC measurements [22-27,45-47]. In DSC measurements, it is assumed that the exothermic heat generated during isothermal cure is proportional to the number of double bonds reacted in the system, so, a measurement of the heat evolved should be an indication of the degree of conversion [29].

The present authors showed [28] that the shrinkage-strain of dental resin-monomers follows the autocatalytic pattern. Therefore, the shrinkage-kinetics of the materials could be used to follow the polymerization behavior. Hence, Eq. (III) was applied to describe the shrinkage-strain rate. The equation can be re-written for modeling of shrinkage as follows:

$$
\frac{\mathrm{d} \varepsilon}{\mathrm{dt}}=k \varepsilon^{m}\left(\varepsilon_{\mathrm{m}}-\varepsilon\right)^{n}
$$

where, similarly, $\varepsilon$ is shrinkage-strain, $\varepsilon_{\mathrm{m}}$ the maximum of the shrinkage-strain measured at a given time (here after $60 \mathrm{~min}$ ), $k$ the shrinkage rate constant, $m$ denotes the shrinkage-strain autocatalytic exponent and $n$ is the shrinkage-strain order exponent.

The kinetic parameters of $k, m$ and $n$ were calculated following the method of Waters and Peddy [48]. They analyzed DSC curves for autocatalyzed reactions and found that

$$
\frac{m}{n}=\frac{\alpha_{\mathrm{rm}}}{1-\alpha_{\mathrm{rm}}}
$$

where $\alpha_{\mathrm{rm}}$ is the reaction extent at the maximum of the polymerization rate curve. Linearization of Eq. (III) gives

$\ln \left(\frac{\mathrm{d} \alpha}{\mathrm{dt}}\right)=\ln k+n \ln \left[\alpha^{m / n}\left(\alpha_{\mathrm{m}}-\alpha\right)\right]$

Having estimated $m / n$ by Eq. (V), the $n$ and $k$ values can be determined from the slope and intercept of the linear plot based on Eq. (VI).

The same procedure was followed to determine the shrinkage-kinetic parameters considering:

$\frac{m}{n}=\frac{\varepsilon_{\mathrm{rm}}}{1-\varepsilon_{\mathrm{rm}}}$

and

$\ln \left(\frac{\mathrm{d} \varepsilon}{\mathrm{dt}}\right)=\ln k+n \ln \left[\varepsilon^{m / n}\left(\varepsilon_{\mathrm{m}}-\varepsilon\right)\right]$ where $\varepsilon_{\mathrm{rm}}$ is the shrinkage-strain at the maximum shrinkagestrain rate.

The calculated parameters for the resin-monomers, containing $65 \mathrm{wt} . \%$ Bis-GMA and $35 \mathrm{wt} . \%$ TEGDMA, are listed in Table 2. The results showed an increase in the rate constant, $k$, with increasing temperature and a slight tendency to decrease in exponents $m$ and $n$, more so for $n$.

The shrinkage rate constant, $k$, is a temperature-dependent Arrhenius-type constant:

$k=A \exp \left(\frac{-E}{R T}\right)$

where $T$ is temperature, $R$ the gas constant and $E$ is the activation energy.

To obtain the values of $A$ and E, Eq. (IX) can be linearized as follows:

$\ln k=\ln A-\frac{E}{R T}$

Shrinkage-strain of the matrix resin was determined for different temperatures $\left(23,35\right.$ and $\left.45^{\circ} \mathrm{C}\right)$ and the $k$ values obtained using Eq. (VIII). The pre-exponential factor, $A$, and $E$ were then calculated by plotting $\ln k$ against (1/T) (Fig. 5).

$E$, which can be considered as the overall activation energy of shrinkage-strain, and A were obtained as: $E=23.8 \mathrm{~kJ} / \mathrm{mol}$ and $A=11.6 \mathrm{~s}^{-1}$.

As the principle of the method is different from the wellknown thermal analysis (DSC), it could be expected that the values may be different from those obtained from thermoanalytical methods.

Shrinkage-strains of the composites containing different filler-contents were also measured (Fig. 4). The shrinkagestrain decreased with increase of filler-volume percent. Incorporating inorganic fillers into the resin-monomers resulted in a reduction of monomer percentage in the composite leading to a decrease in their volumetric shrinkage. The results (Fig. 5) indicate that the shrinkage decrease was linearly proportional to the filler-volume percent $\left(r^{2}>0.98\right)$. Fig. 5 also shows that the mixture law gave a good estimation of the shrinkage-strain when the filler content was expressed as volume percent:

$\varepsilon_{\text {total }}=\varepsilon_{\mathrm{f}} \phi_{\mathrm{f}}+\varepsilon_{\mathrm{m}} \phi_{\mathrm{m}}$

where $\varepsilon$ is shrinkage, $\phi$ denotes volume percent (or fraction) and subscripts $\mathrm{f}$ and $\mathrm{m}$ stand for filler and matrix, respectively. As fillers do not undergo polymerization contraction $\left(\varepsilon_{\mathrm{f}}=0\right)$, the equation reduces to:

$\varepsilon_{\text {total }}=\varepsilon_{\mathrm{m}} \phi_{\mathrm{m}}=\varepsilon_{\mathrm{m}}\left(1-\phi_{\mathrm{f}}\right)$

The dashed line in Fig. 5 represents Eq. (XII).

The shrinkage-strain rates calculated for the composites with different filler contents are presented in Fig. 6 . The composites followed the same autocatalytic pattern as the matrix resin. The maximum shrinkage-strain rate and time at the maximum, two kinetically important points in the rate curves, are illustrated in Figs. 7 and 8. Fig. 7 shows a linear correlation between the maximum shrinkage-strain rate and filler content. The figure also shows that the linear mixture law could 
predict the maximum rate:

$R_{\varepsilon(\text { total })}^{\max }=R_{\varepsilon(\mathrm{m})}^{\max } \phi_{\mathrm{m}}=R_{\varepsilon(\mathrm{m})}^{\max }\left(1-\phi_{\mathrm{f}}\right)$

where $R_{\varepsilon(\text { total })}^{\max }$ and $R_{\varepsilon(\mathrm{m})}^{\max }$ are the maximum shrinkage-strain rate of the composite and the matrix, respectively. The dashed line in Fig. 7 represents Eq. (XIII). It indicates that the decrease in the maximum shrinkage-strain rate is due to the decrease in the matrix monomer percent in the composite. The results also confirm the linearity and reliability of the bonded-disk technique. In this technique, which was introduced and analyzed in detail by Watts and Cash [39], axial-shrinkage is measured. However, with the disc-shape geometry of the sample, which is bonded on one side to a rigid glass surface, the value obtained is close to volumetric shrinkage, to a good approximation [49].

Fig. 8 shows the time at which the maximum shrinkagestrain is reached $\left(t_{\varepsilon(\mathrm{m})}\right)$. As illustrated, there is no significant difference among the $t_{\varepsilon(\mathrm{m})}$ of the composites with different filler contents $(p>0.05)$. The results indicate that the filler loading did not affect the shrinkage-kinetics of the composites. This finding was confirmed by the conversion results.

\subsection{Conversion}

As apparent in Fig. 9, there was no significant difference between the conversions of the composites containing 31-57 volume-percent filler $(p>0.05)$. Halvorson et al. [50], however, found that conversion progressively decreased with increasing filler-loading and concluded that the mobility of resin-monomers can be restricted on the surface of the fillers, leading to a decrease in molecular and radical mobility and resulting in lower conversion. But it seems that the influence of filler on the conversion and reaction kinetics of the composite is more related to filler particle-size and surface-area than filler loading. The fillers which were used in their study were microfillers with an average primary particle size of about $40 \mathrm{~nm}$ and specific surface area of $>50 \mathrm{~m}^{2} / \mathrm{g}$ [51]. In our experiments, the fillers were glass particles with the specific surface area of about $3.7 \mathrm{~m}^{2} / \mathrm{g}$ (Table 1 ), which is much lower than the surface area of the microfillers. Therefore, the effect of the fillers on the mobility of the monomers/radicals is probably very low or negligible. This result is in agreement with the work of Nie et al. [24]. They also found that the addition of inorganic filler (up to $70 \%$ in their study) did not significantly influence the polymerization kinetics.

\section{Conclusions}

Photopolymerization shrinkage measurements revealed that this method can be used as a new way to approach the complex photopolymerization kinetics of dental composites and/or multifunctional monomers. The shrinkage-strain rate of the matrix resin and composites followed an autocatalytic pattern confirming the diffusion-controlled mechanism of the curing reaction of dental composites and resinmonomers. The phenomenological model of Kamal $[29,30]$ satisfactorily described the shrinkage-kinetics of the dental resins. The kinetic parameters were determined by perform- ing the shrinkage measurements at different temperatures. The shrinkage-strain and the maximum shrinkage-strain rate progressively decreased with the increase of filler loading, following a linear pattern which could be well described using the mixture law. The degree of conversion of the photopolymerized resins was not influenced by the filler content, which can be explained considering the relatively low surface area of the filler particles. This finding was confirmed by the shrinkagestrain rate results.

\section{REFERENCES}

[1] Ahn K-D, Chung C-M, Kim Y-H. Synthesis and photopolymerization of multifunctional methacrylates derived from Bis-GMA for dental applications. J Appl Polym Sci 1999;71:2033-7.

[2] Klee JE, Neidhart F, Flammersheim H-J, Mulhaupt R. Monomers for low shrinking composites, 2a: synthesis of branched methacrylates and their application in dental composites. Macromol Chem Phys 1999;200:517-23.

[3] Chung C-M, Kim J-G, Kim M-S, Kim K-M, Kim K-N. Development of a new photocurable composite resin with reduced curing shrinkage. Dent Mater 2002;18:174-8.

[4] Chung C-M, Kim M-S, Kim J-G, Jang D-O. Synthesis and photopolymerization of trifunctional methacrylates and their application as dental monomers. J Biomed Mater Res 2002;62:622-7.

[5] Khatri CA, Stansbury JW, Schultheisz CR, Antonucci JM. Synthesis, characterization and evaluation of urethane derivatives of Bis-GMA. Dent Mater 2003;19:584-8.

[6] Kim Y, Kim CK, Cho BH, Son HH, Um CM, Kim OY. A new resin matrix for dental composite having low volumetric shrinkage. J Biomed Mater Res Part B: Appl Biomater 2004;70B:82-90.

[7] Chen M-H, Chen C-R, Hsu S-H, Sun S-P, Su W-F. Low shrinkage light curable nanocomposite for dental restorative material. Dent Mater 2006;22(2):138-45.

[8] Satsangi N, Rawls HR, Norling BK. Synthesis of low-shrinkage polymerizable liquid-crystal monomers. J Biomed Mater Res Part B: Appl Biomater 2004;71B:153-8.

[9] Watts DC, Al Hindi A. Intrinsic 'soft-start' polymerization shrinkage-kinetics in an acrylate-based resin-composite. Dent Mater 1999;15:39-45.

[10] Lim B-S, Ferracane JL, Sakaguchi RL, Condon JR. Reduction of polymerization contraction stress for dental composites by two-step light-activation. Dent Mater 2002;18:436-44.

[11] Condon JR, Ferracane JL. Reduction of composite contraction stress through non-bonded microfiller particles. Dent Mater 1998;14:256-60.

[12] Condon JR, Ferracane JL. Reduced polymerization stress through non-bonded nanofiller particles. Biomaterials 2002;23:3807-15.

[13] Torstenson B, Oden A. Effects of bonding agent types and incremental techniques on minimizing contraction gaps around resin composites. Dent Mater 1989;5(4):218-23.

[14] Prati C, Montanari G. Comparative microleakage study between the sandwich and conventional three-increment techniques. Quintessence Int 1989;20(8):587-94.

[15] Saunders WP, Strang R, Ahmad I. Effect of composite resin placement and use of an unfilled resin on the microleakage of two dentin bonding agents. Am J Dent 1990;3(4):153-6.

[16] Krejci I, Lutz F. Marginal adaptation of Class V restorations using different restorative techniques. J Dent 1991;19(1):24-32. 
[17] Crim GA. Microleakage of three resin placement techniques. Am J Dent 1991;4(2):69-72.

[18] Santini A, Plasschaert AJ, Mitchell S. Effect of composite resin placement techniques on the microleakage of two self-etching dentin-bonding agents. Am J Dent 2001;14(3):132-6.

[19] St Georges AJ, Wilder Jr AD, Perdigao J, Swift Jr EJ. Microleakage of Class $\mathrm{V}$ composites using different placement and curing techniques: an in vitro study. Am J Dent 2002;15(4):244-7.

[20] Mullejans R, Lang H, Schuler N, Baldawi MO, Raab WH. Increment technique for extended Class $\mathrm{V}$ restorations: an experimental study. Oper Dent 2003;28(4):352-6.

[21] Loguercio AD, Reis A, Ballester RY. Polymerization shrinkage: effect of constraint and filling technique in composite restorations. Dent Mater 2004;20(3): 236-43.

[22] Cook WD. Photopolymerization kinetics of dimethacrylates using the camphorquinone/amine initiator system. Polymer 1992;33(3):600-9.

[23] Maffezzoli A, Della Pietra A, Rengo S, Nicolais L, Valletta G. Photopolymerization of dental composite matrices. Biomaterials 1994;15(15):1221-8.

[24] Nie J, Rabek JF, Linden L-A. Photopolymerization of poly (melamine-co-formaldehyde) acrylate for dental restorative resins. Polym Int 1999;48:129-36.

[25] Khudyakov IV, Legg JC, Purvis MB, Overton BJ. Kinetics of photopolymerization of acrylates with functionality of 1-6. Ind Eng Chem Res 1999;38:3354-9.

[26] Lee IB, Um CM. Thermal analysis on the cure speed of dual cured resin cements under porcelain inlays. J Oral Rehab 2001;28:186-97.

[27] Stansbury JW, Dickens SH. Network formation and compositional drift during photo-initiated copolymerization of dimethacrylate monomers. Polymer 2001;42:6363-9.

[28] Atai M, Watts DC, Atai Z. Shrinkage strain-rates of dental resin-monomer and composite systems. Biomaterials 2005;26:5015-20.

[29] Kamal MR, Sourour S. Kinetic and thermal characterization of thermoset cure. Polym Eng Sci 1973;13(1): 59-64.

[30] Kamal MR. Thermoset characterization for moldability analysis. Polym Eng Sci 1974;14(3):231-9.

[31] Söderholm KJM. Influence of silane treatment and filler fraction on thermal expansion of composite resins. J Dent Res 1984;63(11):1321-6.

[32] Li Y, Swartz ML, Philips RW, Moore BK, Roberts TA. Effect of filler content and size on the properties of composites. J Dent Res 1985;64(12):1396-401.

[33] Germain SST, Swartz ML, Philips RW, Moore BK, Roberts TA. Properties of microfilled composite resins as influenced by filler content. J Dent Res 1985;64(2):155-60.
[34] Chung K-H, Greener EH. Correlation between degree of conversion, filler concentration and mechanical properties of posterior composite resins. J Oral Rehab 1990;17:487-94.

[35] Taylor DF, Kalachandra S, Sankarapandian M, McGrath JE. Relationship between filler and matrix resin characteristics and the properties of uncured composite pastes. Biomaterials 1998;19:197-204.

[36] Kobayashi M, Shinzato S, Kawanabe K, Neo M, Matsushita M, Kokubo T, Kikutani T, Nakamura T. Alumina powder/Bis-GMA composite: effect of filler content on mechanical properties and osteoconductivity. J Biomed Mater Res 2000;49:319-27.

[37] Lim B-S, Ferracane JL, Condon JR, Adey JD. Effect of filler fraction and filler surface treatments on wear of micro filled composites. Dent Mater 2002;18:1-11.

[38] Atai M, Nekoomanesh M, Hashemi SA, Amani S. Physical and mechanical properties of an experimental dental composite based on a new monomer. Dent Mater 2004;20:663-8.

[39] Watts DC, Cash AJ. Kinetic measurements of photo-polymerization contraction in resins and composites. Meas Sci Technol 1991;2:788-94.

[40] Lovell LG, Stansbury JW, Syrpes DC, Bowman CN. Effects of composition and reactivity on the reaction kinetics of dimethacrylate/dimethacrylate copolymerizations. Macromolecules 1999;32:3913-21.

[41] Andrzejewska E. Photopolymerization kinetics of multifunctional monomers. Prog Polym Sci 2001;26:605-65.

[42] Watts DC. Reaction kinetics and mechanics in photo-polymerised networks. Dent Mater 2005;21:27-35.

[43] Odian G. Principle of polymerization. 2nd ed. John Wiley \& Sons, Inc.; 1981.

[44] Anseth KS, Wang CM, Bowman CN. Kinetic evidence of reaction diffusion during the polymerization of multi (meth) acrylate monomers. Macromolecules 1994;27:650-5.

[45] Andrzejewska E, Linden L-A, Rabek JF. Modelling the kinetics of photoinitiated polymerization of di(meth)acrylates. Polymer Int 1997;42:179-87.

[46] Maffezzoli A, Terzi R. Effect of irradiation intensity on the isothermal photopolymerization kinetics of acrylic resins for stereolithography. Thermochim Acta 1998;321:111-21.

[47] Lecamp L, Youssef B, Bunel C, Lebaudy P. Photoinitiated polymerization of dimethacrylate oligomers: 2. Kinetic studies. Polymer 1999;40:1403-9.

[48] Waters DN, Paddy JL. Equations for isothermal differential scanning calorimetric curves. Anal Chem 1988;60:53-7.

[49] Weinmann W, Thalacker C, Guggenberger R. Siloranes in dental composites. Dent Mater 2005;21:68-74.

[50] Halvorson RH, Erickson RL, Davidson CL. The effect of filler and silane content on conversion of resin-based composite. Dent Mater 2003;19:327-33.

[51] Technical bulletin pigments, no. 11. Basic characteristic of AEROSIL $^{\circledR}$. 5th ed. Germany: Degussa; 1997. 